IP Periodica Polytechnica

Transportation Engineering

44(4), pp. 215-221, 2016

DOI: $10.3311 /$ PPtr. 8795

Creative Commons Attribution (i)

RESEARCH ARTICLE

\section{How Expressway Geometry Factors Contribute to Accident Occurrence? A Binary Logistic Regression Study}

\author{
Changkun Chen ${ }^{1}$, Yonggang Wang ${ }^{1 *}$, Chengxi Ma ${ }^{1}$, Wei Zhang ${ }^{2}$
}

Received 09 November 2015; accepted 22 March 2016

\begin{abstract}
Logistic regression and statistical method are combined to analyze accident data from "Traffic Accident Database System" (TADS) in order to find the relationship between expressway geometric factors and accident rate. A total of 2004 observations are used to illustrate the proposed model. A new concept mean angle of deflection (MAD) is also introduced to evaluate the effect of horizontal alignment. Accident rate (the dependent variable) in this study is a dichotomous variable, so a binary logistic regression is found suitable. Totally sixteen variables are proposed and fourteen are used in the model. Eight variables are found significantly associated with accident rate at the 0.05 significance. Each variable is interpreted with the results of SPSS 19.0 and the results provide the references for identifying unsafe locations and taking appropriate counteractive measures for expressways in mountainous areas.
\end{abstract}

\section{Keywords}

Accident rate, Logistic regression, Expressway, Curve, Variables

\footnotetext{
${ }^{1}$ School of Highway, Chang' an University, Xi'an 710064, China

${ }^{2}$ Shaanxi Provincial Highway Bureau, Xi'an 710068, China

"Corresponding author, e-mail: wangyg@chd.edu.cn
}

\section{Introduction}

During the past decades, the number of registered vehicles has witnessed a dramatic increase in China. By the end of 2013, according to the statistics by the Ministry of Public Security, the registered vehicles have risen from 9.6 million in 2003 to 2.5 billion in 2013. As a result, a great amount of traffic accident has occurred, especially on mountainous expressways. Number of deaths resulting from expressway accidents has increased by 10.2 times from 616 persons in 1995 to 6300 persons in 2010 , and the average annual increase was 17.9 percent over the past 15 years (Zhao and Deng, 2012). Though expressway network comprises only $1.85 \%$ of total road mileage, its reported traffic deaths are as large as 13.54 percent of all traffic fatalities. At present, some countermeasures have been implemented to enhance the traffic safety of expressways, especially for those in mountainous areas. Undoubtedly, these measures could bring a slight decrease in number of accidents, but the fatality rate is still alarming during the forthcoming years.

A large set of potential factors contributes to the occurrence of expressway accidents, including human behaviors, automobiles states, roadway geometrics and environmental conditions, etc (Lee et al., 2008; Gregoriades and Mouskos, 2013). Thus many previous studies have focused their emphasis on the likelihood of accidents with those factors, among which human factors from human skills (Sivak, 1981), driving fatigue (Di Milia et al., 2011) and age and gender (Bener et al., 2013) have been given considerable attention. Moreover, some have studied the weights and bumper of vehicles (Gattis et al., 1996; Matsui, 2005) and some have investigated the effects of weather conditions and traffic composition on the occurrence of accidents (Bergel-Hayat et al., 2013; Ramírez et al., 2009), but the important role of roadway geometric design is often neglected.

An unreasonable design of road alignment may lead to hazardous driving conditions. Actually, it is difficult to estimate and determine how much the expressway geometric factors contribute to the likelihood of accident occurrence because there is no valid, practical and simple instrument for traffic polices to examine effects of each individual factor on accidents. 
Therefore, how to determine the proportion of human, vehicle, roadway and environment becomes a worldwide concern. In New Zealand, roadway factors and over speeding behavior have been identified as two significant factors contributing to $35 \%$ and $28 \%$ of fatal and serious expressway accidents (source: NZ Transport Agency Research Report 371), respectively, and similar findings have also been observed in 8 mountainous expressways in China (Wang et al., 2010). Islam et al. (2014) considered the expected number of crash counts, traffic volume and roadway and roadside geometries such as number of lanes, shoulder width, and median type to establish safety performance functions (SPFs) so as to predict the single-vehicle and multivehicle crashes.

Many previous studies have indicated that curves witness a higher accident rate, so vertical and horizontal curvature have been recognized as two considerable factors associated with driving safety. For example, brake failure on huge grade segments accounts for quite a number of accidents, so the reduction of average gradient is more helpful to prevent accidents (Fu et al., 2011). For vertical and horizontal alignments, it is important to keep themselves continuous (Camacho-Torregrosa et al., 2013). Moreover, transitioned vertical curve is proposed to limit the length and gradient of vertical curve to ensure driving safety (Easa and Hassan, 2000). Sight distance is another key variable concerned in geometric design. Therefore, previous researches have used a great number of mathematical methods to analyze the relation between geometric design and likelihood of accident occurrence, such as binomial regression (Milton and Mannering, 1998), Poisson regression (Miaou et al., 1994), Bayesian hierarchical approach (Deublein et al., 2013), multivariate pobit regression and random-parameters pobit models (Anastasopoulos et al., 2012).

Few studies, however, have focused on the specific conditions in China, especially in the mountainous areas. Therefore, the objective of this research is to (i) analyze the data collected in two typical mountain expressways (Taigan and Changjin Expressways) and measure the quantitative relationship between geometric design variables and the likelihood of accidents; (ii) find which factors among length, grade and radius contribute significantly to accidents, identify the combined influence of horizontal and vertical curves, and pick out some unsafe segments; and (iii) propose the corresponding safety improvement measures.

\section{Method}

\subsection{Data collection}

The traffic accident data in this study is collected from "Traffic Accident Database System" (TADS), which is published by Ministry of Public Security of the People's Republic of China and maintained by Jiangxi Transport Policy Bureau. This system provides accurate and detailed accident information including location, roadway conditions, number of vehicles involved, crash type and major causes, individual messages of driver involved, weather conditions, et al.

The original accident database contains 58131 officially reported observations occurring in Jiangxi, China over the period of 2008-2013, in which 14983 samples are collected from expressways. In this study, two typical sections of expressways are chosen among roadway networks in Jiangxi, including a $128 \mathrm{~km}$ section of Taigan Expressway (G45) and a $128 \mathrm{~km}$ section of Changjin Expressway (G065), as shown in Fig. 1, and 2004 valid accident samples are considered for further analysis from 2196 observations on these two expressway sections, accounting for $13.38 \%$ of the total number in Jiangxi expressways.

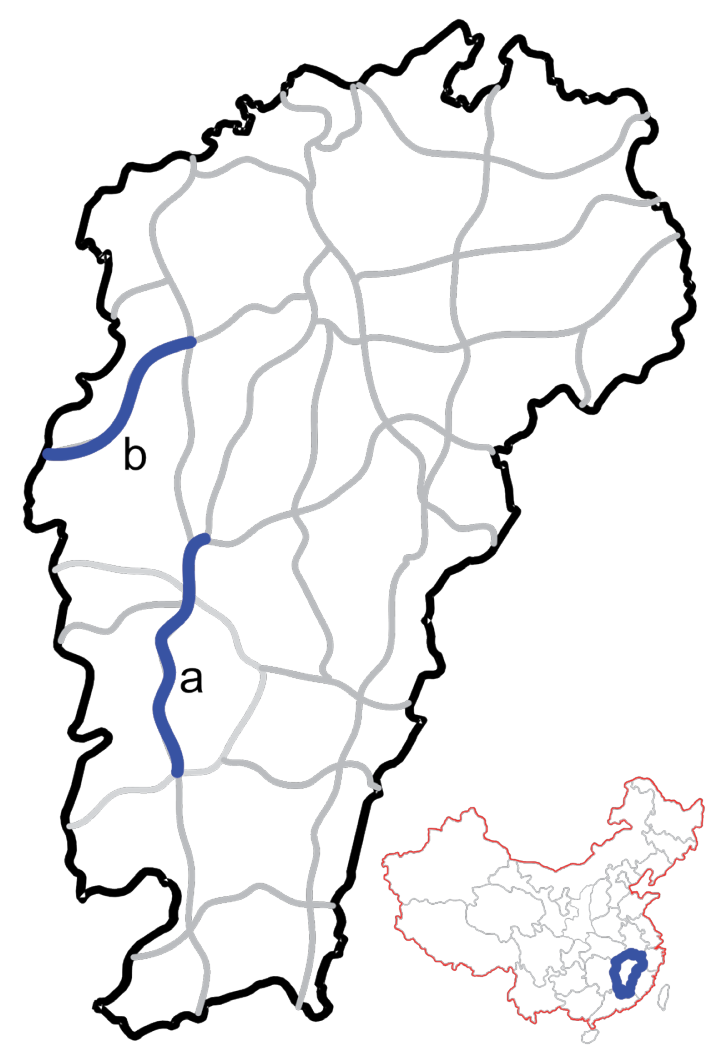

Fig. 1 Location of Taigan and Changjin Expressways in Jiangxi, China. a. Taigan Expressway, b. Changjin Expressway. Note: Jiangxi, also called "Gan" for short, is located in the southeastern part of Mainland China, on the southern bank of the Yangtze River, covering a total area of 166,900 sq km with a population of about 45.42 million by the end of 2014. Now, it has a total provincial road network of $155,515 \mathrm{~km}$, divided in five administrative levels: 4,515 km of expressway (marked in grey lines), 1,902 km of a firstclass highway, 9,941 km of a second-class highway, 10,619 km of a thirdclass highway, and an additional $101,315 \mathrm{~km}$ of a forth-class highway.

\subsection{Variables}

Data pertaining to 6 years $(2008-2013)$ are made available by the TADS from the system. For purpose of this study, the valid information are picked out and combined manually into one file. It contains location, horizontal alignment (radius of curve, length of curve, angle of deflection), vertical alignment (direction of grade, direction of grade) and $A A D T$ (annual average day traffic). Also in order to estimate the number of accidents, accident rate $(A R)$ is determined as: 


$$
A R=\frac{N^{*} 10^{8}}{A A D T^{*} L^{*} D}
$$

where $A R$ is number of accidents per 100 million vehicle-mile of travel, $N$ is total number of accidents in the study period, $L$ is length of each segment $(\mathrm{km})$, and $D$ is the days of study period.

Key variables in this paper include $A R, N, \mathrm{R}$ (radius of curve), $L, M A D$ (mean angle of deflection) $=N / L, P G$ (percent grade), $D G$ (direction of grade) including line, concave and convex. Additionally, three distinct zones are defined as:

(1) zone 1 (entrance zone): $100 \mathrm{~m}$ before and after the entrance;

(2) zone 2 (inside zone): between zone 1 and zone 3; (3) zone 3 (exit zone): $100 \mathrm{~m}$ before and after the exit. $\mathrm{TZ}_{1}, \mathrm{TZ}_{2}, \mathrm{TZ}_{3}$ and $\mathrm{RZ}_{1}, \mathrm{RZ}_{2}, \mathrm{RZ}_{3}$ are the distinct zones (see Fig. 2) of tunnel and ramp. Statistical variables are presented in Table 1.

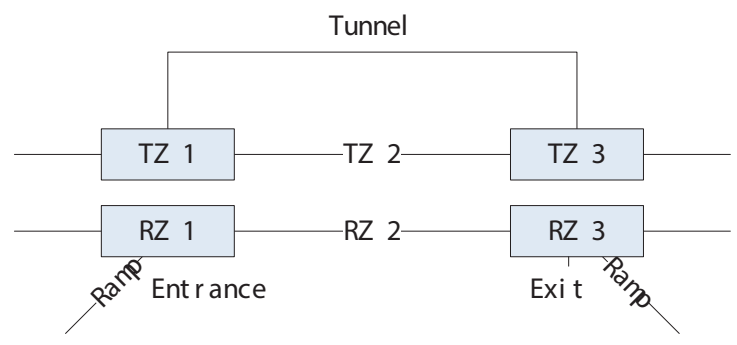

Fig. 2 Distinct zones of tunnel and ramp

Table 1 Key variables used for regression analysis

\begin{tabular}{|c|c|c|c|c|}
\hline Variable & Min & $\operatorname{Max}$ & Mean & SD \\
\hline$R$ & 0 & 6000.000 & 2122.031 & 1853.201 \\
\hline $\mathrm{C}$ & 0 & 66.920 & 20.986 & 17.810 \\
\hline$N$ & 1.000 & 31.000 & 4.742 & 2.302 \\
\hline$M A D$ & 13.910 & 1641.970 & 182.147 & 247.408 \\
\hline$L$ & 0.010 & 1.850 & 0.223 & 0.215 \\
\hline$P G$ & -4.000 & 3.900 & 0.039 & 1.937 \\
\hline \multirow[t]{2}{*}{$A R$} & 13.910 & 641.970 & 133.708 & 118.728 \\
\hline & line & & & 910 \\
\hline \multirow[t]{3}{*}{$D G$} & convex & & $N$ & 426 \\
\hline & concave & & & 665 \\
\hline & $\mathrm{TZ}_{1}$ & & & 92 \\
\hline \multirow[t]{3}{*}{ Tunnel zone } & $\mathrm{TZ}_{2}$ & & $N$ & 44 \\
\hline & $\mathrm{TZ}_{3}$ & & & 88 \\
\hline & $\mathrm{RZ}_{1}$ & & & 79 \\
\hline \multirow[t]{2}{*}{ Ramp zone } & $\mathrm{RZ}_{2}$ & & $N$ & 24 \\
\hline & $\mathrm{RZ}_{3}$ & & & 65 \\
\hline
\end{tabular}


Table 3 Description of segment length and number of accidents on curves

\begin{tabular}{lrrr}
\hline $\begin{array}{l}\text { Length of curve } \\
(\mathbf{k m})\end{array}$ & $\begin{array}{r}\text { \% of } \\
\text { total } \\
\text { curves }\end{array}$ & $\begin{array}{r}\text { \% total accidents } \\
\text { on curves }\end{array}$ & Ratio \\
\hline $0-0.5$ & 39.985 & 49.333 & 0.811 \\
$0.5-1$ & 45.529 & 41.333 & 1.102 \\
$1-1.5$ & 9.682 & 6.667 & 1.452 \\
$1.5-2$ & 4.804 & 2.667 & 1.802 \\
\hline
\end{tabular}

Figure 3 displays the relationship between $R$ and $A R$ (mean $A R=0.351)$. Obviously, it shows the decrease of $A R$ with the increase of $R$ value. When $R$ ranges between $1000 \mathrm{~m}$ and $1500 \mathrm{~m}$, drivers are more likely to make mistakes that could result in accidents.

As shown in Table 1, the average radius of curves is $2122.031 \mathrm{~m}$. Also, when $R$ is less than or greater than $2000 \mathrm{~m}$, $A R$ is more than or less than $150 \mathrm{~m}$, respectively. Thus $2000 \mathrm{~m}$ can be defined as the threshold. If $R<2000 \mathrm{~m}$, it is a dangerous curve that should be paid more attention.

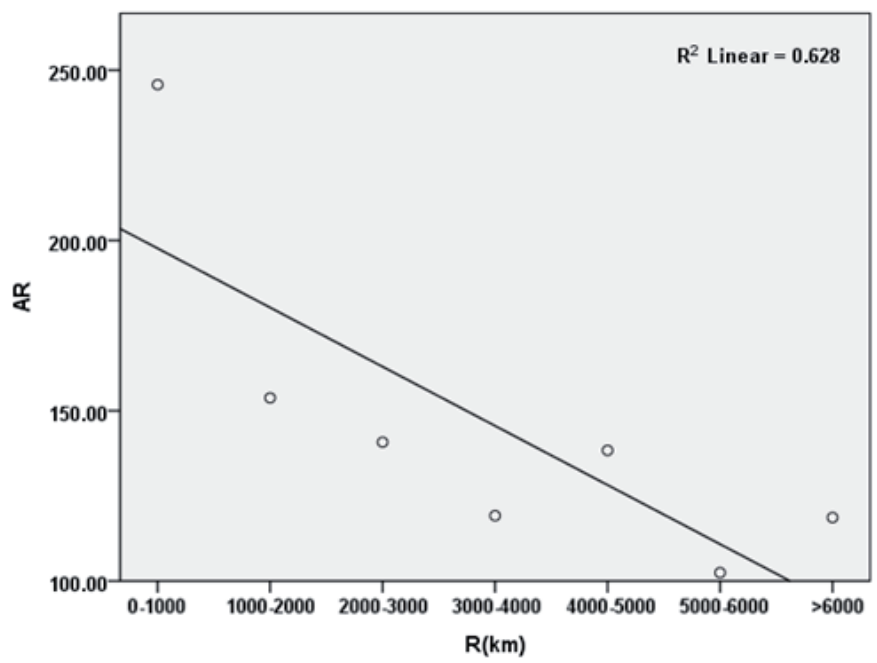

Fig. 3 The distribution of radius and accident rate

From Table $1, M A D$ of curves varies from $13.910^{\circ}$ to $161.970^{\circ}$. And the values of $M A D$ are significantly greater on curves is far higher in interval $\left(700^{\circ}, 800^{\circ}\right)$, as displayed in Fig. 4 . The trend line indicates that $A R$ decreases with the increase of $M A D$. When the $M A D<300^{\circ}, A R$ becomes stable relatively and the value of $A R$ is lower. So $M A D=300^{\circ}$ is considered as the threshold.

\subsection{Effects of vertical curve on accident rate}

Figure 5 displays the distribution of $P G$ and number of accidents. Obviously, the number of accidents increases as $P G$ declines. When $P G=0$, the number of accidents occurring on curves is lowest. Also, $A R$ is relatively low among the interval $-1^{\circ}$ to $1^{\circ}$ that can be considered as the threshold. Moreover, the amount of accidents occurring on descent curves is greater than that on ascent ones.

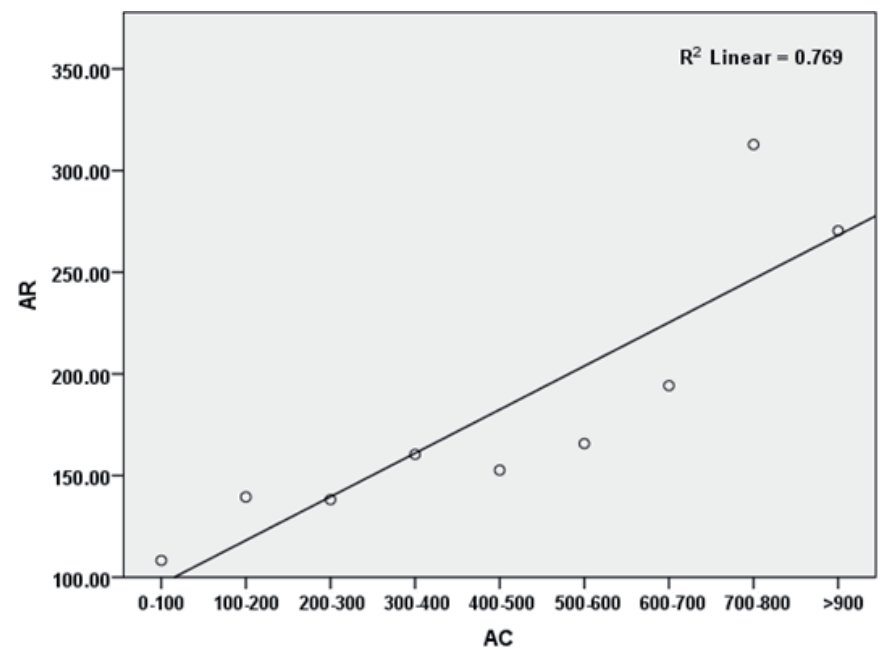

Fig. 4 Distribution of mean angle of deflection and accident rate

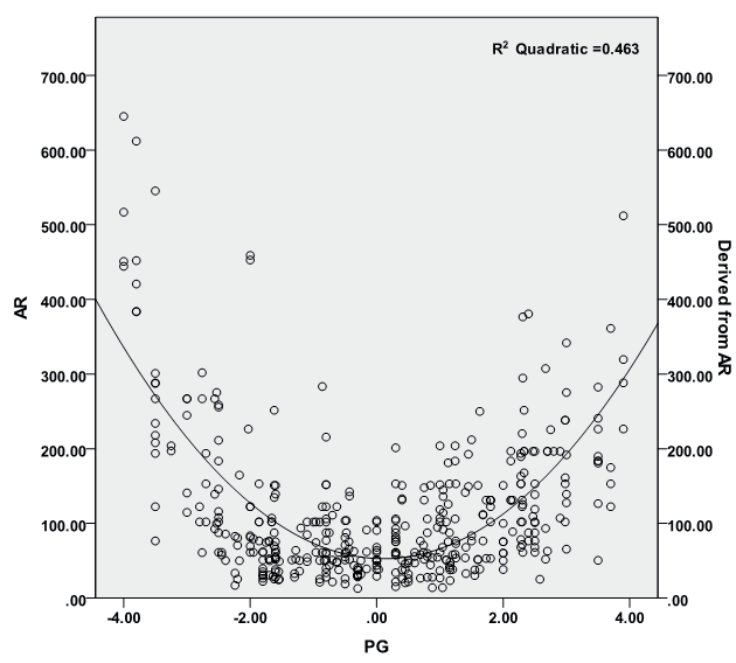

Fig. 5 Distribution of percent grade and accident rate

Table 1 shows that 1091 accidents, accounting for more than a half of total observations, occurred on curves. Figure 6 presents the relationship of direction of grade and number of accidents. The number of accidents occurring on curves with different $D G$ varies significantly. The convex curve is prone to cause more accidents when $P G$ is positive; otherwise, the concave curve tends to induce more injuries and fatalities if $P G<0$. The number of accidents occurring on line curves is relatively stable with the change of $P G$.

\subsection{Result of Logistic regression analysis}

The logistic regression model is processed in SPSS 19 and the model's significant variables and goodness of fit are presented in Table 4. Additionally, Wald $\chi^{2}$ test is used to determine the factors that affect the $A R$. Eight variables are found significantly at the 0.05 significance level in SPSS univariate analysis. $B$ is the coefficient of each factor in the data analysis model.

Therefore, by the analysis result in Table 4, the regression model can be determined as: 

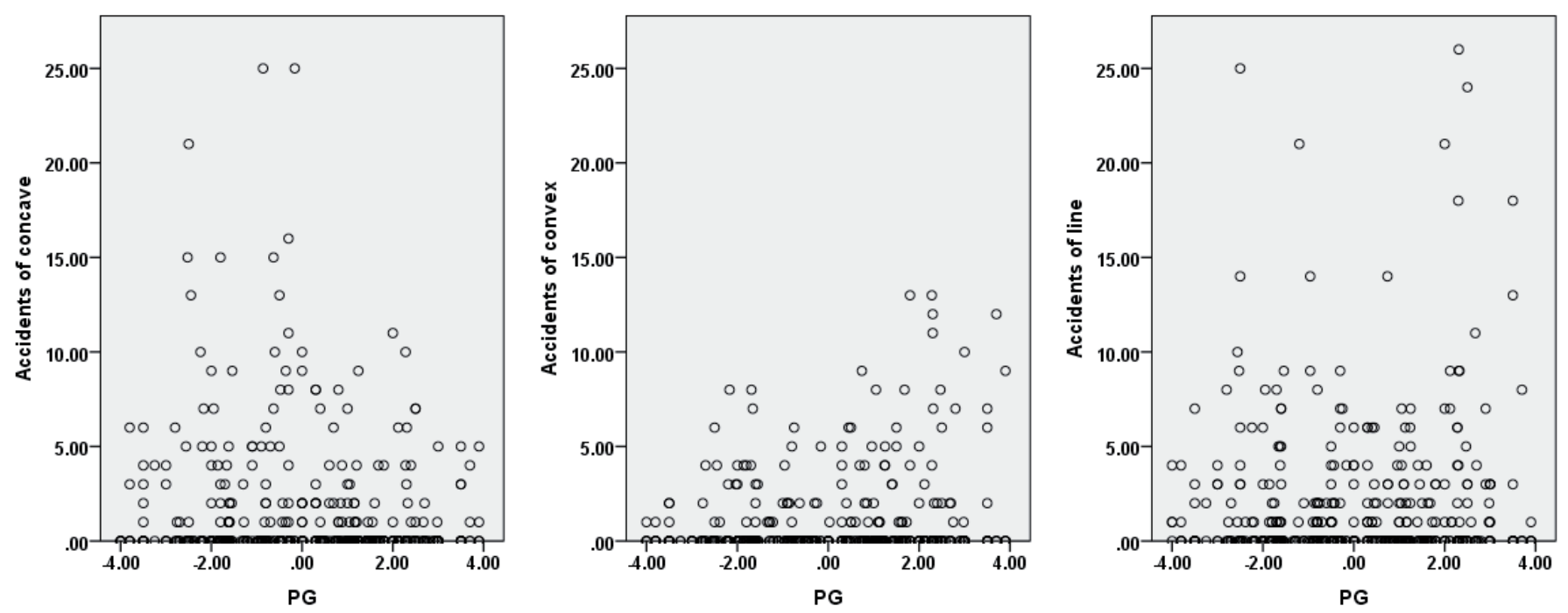

Fig. 6 Features of accidents among concave, convex and line

$\mathrm{Z}=-0.524 R_{1}+1.240 M A D_{1}+0.734 P G_{1}-1.782 L_{1}-0.09 \mathrm{~L}_{2}$

$-0.639 C C-0.210 C V+1.331 T Z_{11}-2.395 T Z_{21}+1.265 T Z_{31}$

$+0.865 R Z_{11}-0.463 R Z_{21}+0.407 R Z_{31}-0.337$

$\mathrm{P}(A R>100)=\mathrm{e}^{\wedge} \mathrm{z} /\left(1+\mathrm{e}^{\wedge} \mathrm{z}\right)$

Table 4 SPSS analysis results of logistic regression model

\begin{tabular}{lcccccc}
\hline Variables & B & S.E. & Wald & df & Sig. & Exp(B) \\
\hline$R_{1}$ & -0.524 & 0.266 & 3.894 & 1 & 0.048 & 0.592 \\
$P G_{1}$ & 0.734 & 0.235 & 9.774 & 1 & 0.002 & 2.084 \\
$M A D_{1}$ & 1.240 & 0.317 & 15.342 & 1 & 0.000 & 3.456 \\
$L_{1}$ & -1.782 & 0.500 & 12.717 & 1 & 0.000 & 0.168 \\
$L_{2}$ & -0.009 & 0.395 & 0.000 & 1 & 0.983 & 0.991 \\
$\mathrm{CC}$ & -0.639 & 0.402 & 2.532 & 1 & 0.112 & 0.528 \\
$\mathrm{CV}$ & -0.210 & 0.405 & 0.270 & 1 & 0.603 & 0.810 \\
$\mathrm{TZ}_{11}$ & 1.331 & 0.476 & 7.824 & 1 & 0.005 & 3.784 \\
$\mathrm{TZ}_{21}$ & -2.395 & 0.510 & 22.099 & 1 & 0.000 & 0.091 \\
$\mathrm{TZ}_{31}$ & 1.265 & 0.502 & 6.341 & 1 & 0.012 & 3.542 \\
$\mathrm{RZ}$ & 0.865 & 0.413 & 4.384 & 1 & 0.036 & 2.375 \\
$\mathrm{RZ}_{21}$ & -0.463 & 0.379 & 1.490 & 1 & 0.222 & 0.630 \\
$\mathrm{RZ}_{31}$ & 0.407 & 0.446 & 0.830 & 1 & 0.362 & 1.502 \\
$\mathrm{Constant}$ & -0.337 & 0.400 & 0.708 & 1 & 0.400 & 0.714 \\
\hline
\end{tabular}

This model shows the confounding effects and interactions between the factors from the univariate analysis. The S.E implies the stand deviation of the coefficient. The $\operatorname{Exp}(B)$ gives the degree of each factor contributing to the accident. With the increase of $\operatorname{Exp}(\mathrm{B})$ of each variable, it is more likely to cause accidents.

Since the $\mathrm{B}$ value of $R_{1}$ is -0.542 , it indicates that with the increase of $R_{1}$, the likelihood of accidents occurring on curves will decrease. Moreover, driving on small radius curves is more risky for drivers due to nervous feeling and more frequent risky driving behaviors.

The results of $M A D$ analysis indicate this variable is effective in describing the likelihood of accident occurrence. The model $(\operatorname{Exp}(\mathrm{B})=3.456)$ shows that $M A D$ has the most significant effect on the occurrence of accidents among all independent variables. As the $M A D$ increases, the likelihood of accidents also rises because these segments produce centripetal and centrifugal forces. Also, the sight distance is not enough to ensure safety and efficient operation of vehicles.

$P G_{1}$ is also a significant risk factor and an increase in the percentage grade tends to induce the increase of accident rate. The empirical analysis reveals that vertical alignment influences accident rate until $P G>1$. Similar results are also found that more accidents have occurred on descent curves than on ascent curves. In some developing countries, however, vehicle's overload contributes more to this type of accidents. The $D G\left(L_{1}, L_{2}, C C\right.$ and $\left.C V\right)$ is not a statistically significant risk factor. In particular, the results in Table 4 illustrate that line segments are more prone to cause accidents than convex and concave segments, and convex is more risky.

The $\operatorname{Exp}(\mathrm{B})=0.168$ of $L_{1}$ is the low among all variables indicates length has a little effect on accidents. According to the $\mathrm{B}$ of length variable, as the length increases the accident rate decreases. This is inconsistent with the previous findings as the length of expressway segment increase so does the exposure to accident. Actually, this is an empirical finding with the regard to the effect of length on accident rate in mountainous area. In mountainous area there are few long straight lines and the geometric alignment is very complicated so in this paper the result is reasonable. But in plain the result may be different.

In mountainous areas, tunnel helps ensure the smooth-going of expressway alignment, but it increases the likelihood of an accident. The regression result also shows that the existence of tunnel has a significant effect on accident rate, which 
is significantly higher at the entrance and exit locations but relatively lower inside tunnel. Similar results have also been reported in previous studies (Jurado-Piña et al., 2010; Yeung and Wong, 2013). At these locations, the sudden change of environment has an adverse effect on driver's perception and judgment of environment information, which easily result in the significant increase of risky driving behaviors and probability of being involved in a crash. Inside tunnel, however, drivers have already adapted to the traffic environment and thus can pay more attention on the wheel, so the accident rate decreases greatly.

On the other hand, the entrance of ramp is also found to affect the accident rate significantly, which drivers also confront too complex traffic environment to acquire traffic condition or route diversion information, so drivers easily make driving errors or even cause fatal crashes (Sarhan et al., 2008). Particularly, $\operatorname{Exp}(\mathrm{B})$ of $M A D_{1}$ (3.456), $\mathrm{TZ}_{11}$ (3.784) and $\mathrm{TZ}_{31}$ (3.542) is much greater than that of other independent variables, so we can see the combination of these factors will increase the risk of driving greatly due to driver's heavy psychological load induced by nervousness and insufficient sight distance. More extremely, a segment with both high $M A D$ and $P G$ is also prone to cause accident.

\section{Conclusions}

Using the statistical traffic accident data from Taigan and Changjin Expressways in Jiangxi, China, this study examines the effects of geometric factors on accident rate and then uses a logistic regression model to determine the likelihood and assess the significant contributory factors to the accident rate. The $\operatorname{Exp}(\mathrm{B})$ given from the SPSS analysis results priorities the geometric factors in the process of expressway design so as to reduce the potential accidents. Also, it helps improve the overall safety performance through setting traffic signs and markings.

Following the analysis results of logistic regression, some recommendations are given as: 1) MAD should be given priority, which is strongly suggested to be no more than 300 . If $M A D>600$, driving speed should be seriously slowed down so as to ensure adequate reaction time and stopping distances at sharp turns; 2) $P G$ should be limited between -2 and 2 . Extension of vertical alignment can reduce traffic accidents, but it is too expensive to be widely used. Other safety improvement measures, such as setting emergency lane and climbing lane, may be more effective; 3 ) it should avoid curves with greater $M A D$ and $P G ; 4)$ for the entrance and exit locations of tunnel and ramp, $M A D$ and $P G$ should be lowered; 5) in view of a sharp curve, driving speed should be limited with full consideration of geometric effects and driver's reaction requirement, and some effective signs can be used to guide driver's sight.

It is important to note that the combination of statistic method and logistical regression provides a superior statistic fit to assess the severity of traffic accidents, but it had some obvious methodological limitations. First, this study sample was not representative of all the expressways in China. Second, the traffic accident data may potentially contain inaccuracies and even not be reliable because of faulty records. Finally, a vast number of crashes and injuries are likely to go unreported, and consequently their correlation with geometric factors may be dramatically underestimated. These research findings can be seen as a contribution to the understanding of relationship between expressway geometric factors and risk of crash. The authors believe that this is an important topic that has not paid enough attention to scientific research. Therefore, further studies will rely on collecting the accurate accident data and evaluating the multiple effects of geometric factors on expressway's accident features. Also, it might also be helpful to explore potential policy initiatives and safety promotion strategies to increase driving safety on expressway.

\section{Acknowledgement}

This research is supported by the Key Program of Department of Transport of Jiangxi, China (No. 2011C0062).

\section{References}

Zhao, J., Deng, W. (2012) Traffic accidents on expressways: new threat to China. Traffic Injury Prevention, 13(3), pp. 230-238. DOI: $10.1080 / 15389588.2011 .645959$

Sivak, M. (1981) Human factors and highway-accident causation: some theoretical considerations. Accident Analysis \& Prevention, 13(2), pp. 61-64. DOI: 10.1016/0001-4575(81)90020-8

Di Milia, L., Smolensky, M. H., Costa, G., Howarth, H. D., Ohayon, M. M., Philip, P. (2011) Demographic factors, fatigue, and driving accidents: an examination of the published literature. Accident Analysis \& Prevention, 43(2), pp. 516-532. DOI: 10.1016/j.aap.2009.12.018

Bener, A., Dafeeah, E. E., Verjee, M., Yousafzai, M. T., Al-Khatib, H., Nema, N., Mari, S., Choi, M. K., Özkan, T., Lajunen, T. (2013) Gender and age differences in risk taking behaviour in road traffic crashes. Advances in Transportation Studies, 31, pp. 53-62.

Gattis, J. L., Alguire, M. S., Narla, S. R. K. (1996) Guardrail end-types, vehicle weights, and accident severities. Journal of Transportation Engineering, 122(3), pp. 210-214. DOI: 10.1061/(ASCE)0733-947X(1996)122:3(210)

Matsui, Y. (2005) Effects of vehicle bumper height and impact velocity on type of lower extremity injury in vehicle-pedestrian accidents. Accident Analysis \& Prevention, 37(4), pp. 633-640.

DOI: $10.1016 /$ j.aap.2005.03.005

Bergel-Hayat, R., Debbarh, M., Antoniou, C., Yannis, G. (2013) Explaining the road accident risk: Weather effects. Accident Analysis \& Prevention, 60, pp. 456-465. DOI: 10.1016/j.aap.2013.03.006

Ramírez, B. A., Izquierdo, F. A., Fernández, C. G., Méndez, A. G. (2009) The influence of heavy goods vehicle traffic on accidents on different types of Spanish interurban roads. Accident Analysis \& Prevention, 41(1), pp. 15-24. DOI: 10.1016/j.aap.2008.07.016

Wang, Y. G., Chen, K.-M., Hu, L.-W., Pei, Y.-L. (2010) Voluntary killer: Multivariate highway geometric factors contributing to crashes and collisions in China's mountainous regions. Technics Technologies Education Management-TTEM, 5(3), pp. 531-543.

Gregoriades, A., Mouskos, K. C. (2013) Black spots identification through a Bayesian Networks quantification of accident risk index. Transportation Research Part C: Emerging Technologies, 28, pp. 28-43. DOI: $10.1016 /$ j.trc.2012.12.008 
Lee, J.-Y., Chung, J.-H., Son, B. (2008) Analysis of traffic accident size for Korean highway using structural equation models. Accident Analysis \& Prevention, 40(6), pp. 1955-1963. DOI: 10.1016/j.aap.2008.08.006

Islam, M., Ivan, J., Lownes, N., Ammar, R., Rajasekaran, S. (2014) Developing safety performance function for freeways by considering interactions between speed limit and geometric variables. Transportation Research Record, 2435, pp. 72-81. DOI: 10.3141/2435-09

Fu, R., Guo, Y., Yuan, W., Feng, H., Ma, Y. (2011) The correlation between gradients of descending roads and accident rates. Safety Science, 49(3), pp. 416-423. DOI: 10.1016/j.ssci.2010.10.006

Camacho-Torregrosa, F. J., Pérez-Zuriaga, A. M., Campoy-Ungría, J. M., García-García, A. (2013) New geometric design consistency model based on operating speed profiles for road safety evaluation. Accident Analysis \& Prevention, 61, pp. 33-42. DOI: 10.1016/j.aap.2012.10.001

Easa, S. M., Hassan, Y. (2000) Development of transitioned vertical curve II sight distance. Transportation Research Part A: Policy and Practice, 34(7), pp. 565-584. DOI: 10.1016/S0965-8564(99)00037-3

Miaou, S. P. (1994) The relationship between truck accidents and geometric design of road sections: Poisson versus negative binomial regressions. Accident Analysis \& Prevention, 26(4), pp. 471-482. DOI: 10.1016/0001-4575(94)90038-8

Milton, J., Mannering, F. (1998) The relationship among highway geometrics, traffic-related elements and motor-vehicle accident frequencies. Transportation, 25(4), pp. 395-413. DOI: 10.1023/A:1005095725001
Deublein, M., Schubert, M., Adey, B. T., Köhler, J., Faber, M. H. (2013) Prediction of road accidents: A Bayesian hierarchical approach. Accident Analysis \& Prevention, 51, pp. 274-291. DOI: 10.1016/j.aap.2012.11.019

Anastasopoulos, P. C., Mannering, F. L., Shankar, V. N., Haddock, J. E. (2012) A study of factors affecting highway accident rates using the randomparameters tobit model. Accident Analysis \& Prevention, 45, pp. 628-633. DOI: 10.1016/j.aap.2011.09.015

Amundsen, F. H., Ranes, G. (2000) Studies on traffic accidents in Norwegian road tunnels. Tunnelling and Underground Space Technology, 15(1), pp. 3-11. DOI: 10.1016/S0886-7798(00)00024-9

Sarhan, M., Hassan, Y., Abd El Halim, A. O. (2008) Safety performance of freeway sections and relation to length of speed-change lanes. Canadian Journal of Civil Engineering, 35(5), pp. 531-541. DOI: 10.1139/L07-135

Jurado-Piña, R., Pardillo-Mayora, J., Jiménez, R. (2010) Methodology to analyze sun glare related safety problems at highway tunnel exits. Journal of Transportation Engineering, 136(6), pp. 545-553. DOI: 10.1061/(ASCE)TE.1943-5436.0000113

Yeung, J. S., Wong, Y. D. (2013) Road traffic accidents in Singapore expressway tunnels. Tunnelling and Underground Space Technology, 38, pp. 534-541. DOI: 10.1016/j.tust.2013.09.002 